by a simple mechanical analogue, by means of which the conception of absolute temperature is introduced. The determination of specific heats, properties of gases, change of state, Van der Waals's equation, and the critical point are well treated, and an attempt is made to explain the phenomena from the molecular standpoint, so far as this can be done by general reasoning. The author's treatment of thermodynamics, however, does not present any striking divergence from the conventional standpoint in which conservation of energy necessarily occupies a prominent position. Of the chapters on electricity, magnetism and light, we can only say that they appear to form a concise and convenient introduction to the elementary principles of the subject.

As an introductory sketch of the outlines of natural philosophy, the book may be unhesitatingly recommended. The wide range of ground covered renders the treatment somewhat encyclopædic, but a notable feature is the large amount of historical information with which each chapter opens. This alone makes the volume valuable as a work of reference.

Another excellent feature is the large number of examples on nearly every section. Many of these are straightforward numerical calculations based on the bookwork, nearly all of them illustrate some point of physical interest. But it is a pity that the student after reading the question sees the answer before him, instead of having an opportunity to work it out for himself; these answers would be much better placed at the end of the book.

Whether Herr Januschke has succeeded or not in establishing the superiority of the "energetic" method, there can be no doubt that he has produced a text-book which will prove of great use to students, and still more to teachers of physics.

G. H. BRYAN.

\section{THE FERTILITY OF THE LAND.}

The Fertility of the Land. By Isaac P. Roberts. Pp. xvii + 4I5. With forty-five illustrations. (New York : The Macmillan Company. London: Macmillan and Co., Ltd., I897.)

THE sub-title of this volume, "A summary sketch of 1 the relationship of farm-practice to the maintaining and increasing of the productivity of the soil," conveys a comprehensive idea of its scope. It belongs to the Rural Science Series, and Mr. L. H. Bailey, who contributes the preface, bestows upon the book a sort of editorial benediction when he commits himself to the statement, "It is the ripened judgment of the wisest farmer whom I have known." The editor further remarks,

"I confess that I have looked with some apprehension upon the rapid diffusion of experimental science of recent years, for there is danger that this knowledge may overshadow the importance of accustomed farm-practice, and lead the farmer to demand specific rules for each perplexity, and to depend upon the Experiment Station and the teacher for his farming."

The fifteen chapters deal with the following subjects: (I) an inventory of the land; (2) the evolution of the plough ; (3) tilling the land ; (4) conservation of moisture; (5) irrigation and drainage; (6) farm manures; (7) NO. I 465 , VOL. 57 ] manures produced by various animals; (8) the waste of manures; (9) the care, preservation and application of manures; (IO) nitrogen and nitrification ; (I I) the phosphoric acid and potash supply; (I2) commercial fertilisers; (I 3 ) lime and various amendments ; (I4) green manures and fallows; ( 15 ) rotations. The treatment of the subject is thus seen to be fairly discursive, and the omission of, for example, the second chapter on the evolution of the plough would in no way have detracted from the main object of the volume. It may be noted in passing that the part of the implement which is familiarly known in this country as the skim coulter is designated the "jointer or skim plough" by the author; we think the English name is preferable as being more descriptive. Much valuable information is brought together in the volume in a convenient form, whilst mo: $t$ of the assertions made by the author, though they may not always carry conviction, are suggestive in character and calculated to stimulate useful trains of thought in the student's mind. The chief defect of the volume is that it ignores the epoch-making work in which Lawes and Gilbert have been engaged for more than half a century. Neither their names nor the name of Rothamsted are mentioned in the index, nor do we come across any reference to them in the text. As the author, we are told, "has had the advantage of much travel," we can only suppose this omission is intentional. The book, of course, suffers in consequence; to give only one instance, the author has missed entirely the admirable definitions of "fertility" and "condition" as applied by Lawes to the soil, and as usefully adopted for practical purposes by English farmers. That the writer is not altogether successful in his selection of authorities is further apparent from the circumstance that he betrays no knowledge of the researches of Warington in nitrification. There is evidence, however, of much familiarity with continental work, and the title of the thirteenth chapter, "lime and various amendments," has an unmistakably French flavour. The book is well printed and neatly turned out; but the Englishman who respects his mother-tongue will experience a shudder at the strange spectacle presented by certain familiar words spelt in "American."

\section{CRIME AND CRIMINALS.}

Crime and Criminals. By J. Sanderson Christison, M.D. Pp. II7. (Chicago: The W. T. Keenen Company, 1897:)

D. CHRISTISON has been attracted to a subject full of difficult problems, but he makes no very practical contribution to their solution. He is a student in the school of Lombroso, and has been at some pains to investigate the psychological aspects of the criminal The cases he presents are, many of them, interesting enough; but beyond proving the fact that the types of offenders are much the same all the world over, they serve no particular purpose, and they are certainly not sufficient to justify the main point of his book-that our existing penal methods are a failure. He has been helped to this conclusion, moreover, by the single experience of the United States where, in his own words, "crimes are now nearly five times as numerous 